\title{
Small-scale effects of hydrodynamics on the structure of intertidal macroalgal communities: A novel approach
}

\author{
Burel Thomas 1, ${ }^{\text {, }}$ Schaal Gauthier ${ }^{1}$, Grall Jacques 2, Le Duff Michel 2, Chapalain Georges ${ }^{3}$, \\ Schmitt Blondie 1, Gemin Maxence ${ }^{1}$, Boucher Olivier ${ }^{3}$, Ar Gall Erwan ${ }^{1}$
}

\begin{abstract}
${ }^{1}$ Laboratoire des Sciences de l'Environnement Marin, UMR 6539 UBO/CNRS/IRD/IFREMER, Rue Dumont d'Urville, 29280, Plouzané, Brittany, France

2 Institut Universitaire Européen de la Mer. Observatoire du Domaine Côtier, UMS 3113. Université de Bretagne Occidentale, Rue Dumont d'Urville, 29280, Plouzané, Brittany, France

${ }^{3}$ Laboratoire de Génie Côtier et Environnement (LGCE), Cerema, 155 rue Pierre Bouguer, Technopôle Brest-Iroise BP 5, 29280, Plouzané, Brittany, France
\end{abstract}

* Corresponding author : Burel Thomas, email address : thomas.burel@univ-brest.fr

\begin{abstract}
:
Wave height was used as a proxy to assess the effect of hydrodynamics on the development and structure of intertidal North-East Atlantic rocky macroalgal communities (Brittany). The characterization of hydrodynamics at small-scale (about $10 \mathrm{~m}$ ) was performed through wave height in situ monitoring using pressure sensors. Both the diversity and the cover of the macroalgal communities were sampled in parallel. Wave heights exhibit large variations with values ranging from ca. $5 \mathrm{~cm}$ to $1.60 \mathrm{~m}$. We show that wave height directly controls the cover of macroalgal canopies (Pearson's $r$ between -0.62 and -0.39 ). In all communities, most of the fucoid covers regressed with increasing wave height values. By contrast, positive correlations were found at low shore levels between wave heights and the cover of the kelp Laminaria digitata and also of several species of Rhodophyta. Redundancy analysis points out the significant effect of wave height on the inner variability of macroalgal communities, explaining up to $19 \%$ of their upright structure and more than $15 \%$ of the distribution of canopy-forming groups. In assemblages dominated by either Pelvetia canaliculata or Fucus serratus, a significant negative correlation was also evidenced with the index of community structure (Ics), which gives an appraisal of both the structure and the development of macroalgal communities. In conclusion, this study provides a novel experimental approach helping to quantify the effects of hydrodynamics on the structure of macroalgal communities using a small-scale in situ quantification of wave heights, revealing hydrodynamics as the main environmental driver of inner structural variations in seaweed assemblages.
\end{abstract}

\section{Highlights}

Wave heights have a significant effect on the extent of macroalgal canopies. Hydrodynamics explains most of intra-community structural variations. In situ pressure measurements enable smallscale evaluation of wave heights. 
Keywords : macroalgal communities, intertidal zone, rocky shores, wave heights, hydrodynamics, MiniDiver, Brittany 


\section{1. Introduction}

35 On rocky shores, the main factors influencing biocenoses distribution are tide and waves

(Menge and Branch, 2001; Bird et al., 2013). Tidal conditions generate various abiotic and

37 biotic pressures in the intertidal zone (Paine, 1966; Dahlhoff, 2004), inducing vertical zonation of organisms, which is observed globally (Stephenson and Stephenson, 1949).

Rocky shores in the Northern Atlantic are commonly dominated by extensive canopies of seaweeds, which largely structure the habitat and the associated diversity (Little and Kitching, 1996). Fucoids typically dominate the higher and mid-intertidal zone, while Laminariales dominate the lower intertidal and high subtidal environments (Lüning, 1990). These intertidal macroalgae are distributed vertically according to their physiological preferendum, structuring six successive communities, commonly observed on the coasts of Brittany (Ar Gall and Le Duff, 2014).The composition and the extent of these communities vary according to several abiotic factors, including substratum composition, nutrient concentration and hydrodynamics (Boaventura, 2000; Mieszkowska et al., 2013). However, communities do not necessarily respond in the same way to similar environmental pressures highlighting the interest of a 
study based on several well-structured canopies. In that way, the highly diversified megatidal zone of Brittany constitutes a convenient model for such a study compared to rocky shores of less extent that are therefore less differentiated (Ar Gall et al., 2016).

Hydrodynamics is known to be a major driver of intertidal biocenoses composition (Denny and Wethey, 2001; Gilman et al., 2006). In the North-East Atlantic, sheltered shores, where macroalgal canopies are well developed, may be distinguished from exposed shores, where the presence of these canopies is largely reduced, and where sessile animals (e.g. barnacles, mussels) and limpets dominate the substratum (Raffaelli and Hawkins, 1999). As underlined by O'Connor et al. (2011), competition for the substratum on rocky shores occurs mostly between seaweeds and the benthic fauna in wave-exposed sites, whereas sheltered areas are more influenced by grazing. Some seaweed species are nevertheless well-adapted to wave exposed rocks, such as Pelvetiopsis limitata in the North-East Pacific (Abbott and Hollenberg, 1976) or the variety linearis of Fucus vesiculosus in the North-East Atlantic (Want et al., 2014). The effects of hydrodynamics on intertidal organisms is well documented at the species level, including the decrease of drag coefficient in macroalgae (Gaylord et al., 1994) and the modification of either their size (Wolcott, 2007) or their morphology (Denny, 2006). Hydrodynamics results from the combined effect of swell and wave action, caused by windinduced forces far at sea and driven by tide and currents (Holthuijsen, 2010). Hydrodynamics in the intertidal zone has first been investigated indirectly through the presence of characteristic taxa (Ballantine, 1961; Floc'h, 1964; Munda, 1978), which allows a rapid and costless overview of the shore exposure to waves. However, such approaches, although still in use because of their simplicity, are limited by local specificities. Alternative methods based on fetch measurements (i.e. the maximum distance swell and waves may travel without obstacle) have been developed, providing convincing results on the effects of hydrodynamics on intertidal community structure (Baardseth, 1970; Burrows et al., 2008). Approaches based 
on wind measurements depend on the local availability of reliable weather data (Thomas, 1986). Predictive models have also been developed to integrate wave energy and / or wave height at a regional scale (e.g. Holthuijsen, 2010; Reguero et al., 2012; Camus et al., 2013; Guillou and Chapalain, 2015; Rattray et al., 2015). Such models give a framework for local studies and open up new prospects to determine the effect of waves on the shores (Cefalì et al., 2016; Puente et al., 2016). Although aforementioned approaches have provided valuable insights into the relationship between hydrodynamics and intertidal communities, they are of little use at local scale, where small-scale topography (i.e. outcrops, rock orientation, crevices) can induce a variability in hydrodynamic forces actually affecting benthic habitats (Paine and Levin, 1981; Helmuth and Denny, 2003; Le Hir and Hily, 2005). Therefore, in order to characterize the extent of hydrodynamics variability at the metric scale and associated effects on intertidal biota, direct measurements are necessary. However, such measurements are still very rare for intertidal environments (Jones and Demetropoulos, 1968; Bell and Denny, 1994; O'Donnell and Denny, 2008). In situ hydrodynamical measurements are generally carried out using large $(>30 \mathrm{~cm})$ pressure transducers in the intertidal zone, including wave height assessment (Autret et al., 2016; Suanez et al., 2019). Small-size $(c a .10 \mathrm{~cm})$ pressure sensors are currently used to assess water levels and less often tidal variations (Balliston et al., 2018; Van Putte et al., 2019). In this study, small-size pressure sensors have been used as wave height recorders on intertidal rocky shores. The relatively low price of these instruments with regards to the quality of their measurements together with the fact that they can be easily displayed in the field as a constellation, makes it possible to conduct a detailed study of smallscale hydrodynamics. Combined to a concomitant accurate evaluation of the structure of macroalgal communities, this small-scale $(c a .10 \mathrm{~m})$ monitoring could provide data to specify the impact of hydrodynamics at the community level. 
The working hypothesis of this study is that hydrodynamics would explain most of the inner variability observed in both the extent and the structure of macroalgal communities. Based on this hypothesis, three questions may be addressed: (1) in the context macroalgae dominated rocky shores, is wave height an adequate descriptor/proxy of hydrodynamics? (2) is the smallscale approach proposed in this study efficient when trying to characterize hydrodynamics at the community level? (3) do every studied macroalgal communities respond in the same way to hydrodynamics variations? Thus, the effect of hydrodynamics on both the extent and the structure of macroalgal communities has been investigated, using in situ wave height measurements, in parallel to the ecological evaluation of six vertically distributed seaweed assemblages on three rocky shores of Western Brittany.

\section{Material and methods}

\subsection{Sites and communities}

Three sites were studied at the western end of Brittany, open to the Atlantic Ocean (Figure 1). Porsal $\left(48^{\circ} 33.848^{\prime} \mathrm{N} / 4^{\circ} 42.309^{\prime} \mathrm{W}\right)$, Porspoder $\left(48^{\circ} 28.876^{\prime} \mathrm{N} / 4^{\circ} 46.293^{\prime} \mathrm{W}\right)$ and the Isle of Segal $\left(48^{\circ} 26.330^{\prime} \mathrm{N} / 4^{\circ} 47.376^{\prime} \mathrm{W}\right)$ are about $15 \mathrm{~km}$ from each other. Tidal ranges are around 8 $\mathrm{m}$ at Spring tides and the sampling sites are 150 - $500 \mathrm{~m}$ long and $50-200 \mathrm{~m}$ wide. These sites were first selected in order to embrace natural variability from a single coast and waterbody (in the sense of the WFD). They are relatively sheltered locations with a similar extensive intertidal vegetation, presenting the six macroalgal communities usually found in the North-East Atlantic Ocean (Cabioc'h et al., 2014). Macroalgal communities are defined as assemblages dominated by either one or two structuring Fucales or Laminariales (Ar Gall and Le Duff, 2014). Communities of the intertidal zone are dominated from top to bottom by: (1) Pelvetia canaliculata (called Pc in the text), then (2) Fucus spiralis (Fspi), both structuring low $(<30 \mathrm{~cm})$ canopies characterized by a reduced diversity. In the mid intertidal zone two species are co-dominating (3), Ascophyllum nodosum and Fucus vesiculosus (An - Fves) 
123 forming canopies up to $2 \mathrm{~m}$ high and more than $50 \mathrm{~cm}$ high, respectively. Then, in the low intertidal zone, (4) Fucus serratus (Fser) structures a canopy up to $50 \mathrm{~cm}$ and (5) Bifurcaria bifurcata and Himanthalia elongata $(\mathrm{He}-\mathrm{Bb})$, up to $30 \mathrm{~cm}$ for the first one and up to $4 \mathrm{~m}$ high for the second one, are the Fucales co-dominating the lowest level of the intertidal zone. In the subtidal fringe, (6) the kelp Laminaria digitata $(L d)$ forms canopies reaching $3 \mathrm{~m}$ high. Two other kelp species, Saccharina latissima and Saccorhiza polyschides may be found in association in this community. The altitude (average tidal height) of these communities was determined by GIS monitoring and post-treatment with Litto3D® data from the SHOM (Service Hydrographique et Océanographique de la Marine; diffusion.shom.fr): $P$. canaliculata $(6.44 \pm 0.39 \mathrm{~m}), F$. spiralis $(5.71 \pm 0.50 \mathrm{~m})$, A. nodosum $-F$. vesiculosus $(4.29 \pm$ $0.72 \mathrm{~m}), F$. serratus $(2.54 \pm 0.46 \mathrm{~m})$, H. elongata - B. bifurcata $(1.94 \pm 0.48 \mathrm{~m})$, L. digitata $(1.32 \pm 0.47 \mathrm{~m})$

\subsection{Field sampling}

Field sampling was conducted from late winter to mid spring (January to May 2017). Each macroalgal community was sampled at low tide, during a one-week period (Table 1). For each community, thirty-six sampling surfaces or spots (twelve per site), evenly spaced, were determined by both photographs and GPS positioning. The substratum was mainly bedrock avoiding microhabitats (i.e. crevices, pools, boulders, sediments). For the sampling, a mobile $1.65 * 1.65 \mathrm{~m}$ plastic grid structure consisting of 25 quadrats of $33 * 33 \mathrm{~cm}$ was laid on the spot. Cover was visually determined and classified within five percentage intervals: ]0-5[, [525[, [25-50[, [50-75[ and [75-100]. Two complementary methods were used to estimate the respective abundances of different algal species (Figure 2). "Undisturbed" sampling aims at describing the distribution of macroalgal groups during emersion, when thalli are lying on the substratum, giving a characterization of the canopy-forming species. Only dominating species of Phaeophyceae and large groups of flora (other Phaeophyceae, erect and crustose 
Rhodophyta, Chlorophyta) were considered in this method. Macroalgal undisturbed covers were measured on the area defined by the whole mobile structure (approximately $2.72 \mathrm{~m}^{2}$ corresponding to one per spot).

"Upright profile" sampling aims at describing both the horizontal and vertical structures of the macroalgal canopy during immersion. The cover of all seaweed species was estimated based on the vertical projection of their thalli on the substratum, to mimic their habit at immersion.

Only individuals or patches larger than $5 \mathrm{~mm}$ were taken into consideration and classified within the following four strata: crustose, micro-meiobiotic $(<30 \mathrm{~cm})$, macrobiotic $(30-100$ $\mathrm{cm})$ and mega-megalobiotic (> $100 \mathrm{~cm}$ ). Where necessary, species identification was undertaken in the laboratory. In this method, the sampled area was defined by the cumulated surface of three $33 \mathrm{~cm} * 33 \mathrm{~cm}$ quadrats randomly chosen within the structure (i.e. about 0.33 $\mathrm{m}^{2}$ per spot).

\subsection{Acquisition and treatment of hydrodynamic data}

In this study, wave heights were used as a proxy of hydrodynamics and estimated by pressure sensors. Mini-Diver® sensors (Schlumberger Water Services or SWS) were used to measure the absolute pressure $\left(\mathrm{P}_{\mathrm{abs}}\right)$, equal to the sum of atmospheric pressure $\left(\mathrm{P}_{\mathrm{atm}}\right)$ and water pressure $\left(\mathrm{P}_{\text {hydro }}\right)$. A plastic base was screwed to the rock and sensors were additionally fasted with cable ties; this method proved secure and allowed easy removal after measurements. They were programmed to record local pressures during seven consecutive days to include about 12-14 tidal cycles, to span various tidal amplitudes, with a relatively high acquisition frequency $(0.04 \mathrm{~Hz}$ for a $25 \mathrm{~s}$ period, providing a total of 24000 values). For a given community, recording was performed by 36 sensors (12 for each site, one per spot), simultaneously to the sampling of macroalgae. 
171 Once recording was achieved, data were downloaded using Diver-Office ${ }^{\circledR}$ (SWS). $\mathrm{P}_{\text {hydro }}$

172 values were obtained from $\mathrm{P}_{\mathrm{abs}}$ data by substracting local $\mathrm{P}_{\mathrm{atm}}$, acquired by a control probe.

173 Each tide period was treated remotely and a polynomial regression was applied to it in order

174 to remove the tide oscillation itself and to leave secondary pressure oscillations generated by

175 waves and globally representative of wave heights. The twenty highest and the twenty lowest

176 pressure values were then selected to determine the average wave height per tide. This

177 estimator was proven to be similar to the Significant Wave Height, defined as the mean of

178 third of the highest waves in the classical wave-by-wave analysis (e.g. Holthuijsen, 2010) of

179 an ancillary, synchronous and co-located signal sampled at a rate in excess of $2 \mathrm{~Hz}$. Since

180 altitude variations between the sensors within a given community were negligible, average

181 wave heights were not corrected.

182

183

184

185

186

187

188

189

190

191

192

193

194

\subsection{Data treatment and statistics}

For both types of community sampling (undisturbed and upright profile), medians of percentage intervals were used to calculate the average cover of taxa or groups of taxa per community. Data from upright profile sampling were used for the calculation of diversity indices. The mean species richness was defined as the total number of species / taxa determined per sampled spot and averaged per community. Furthermore, the Shannon-Wiener index and the Rhodophyta / Phaeophyceae specific richness ratio (R/P ratio) were calculated for each sampled spot. The development and structural state of each macroalgal community was evaluated by the index of community structure (Ics) (Ar Gall and Le Duff, 2014), which takes into account the cover of taxonomic, stratum and structural / functional groups of seaweeds. Wave height values were treated after standardization of the variable.

All analyses were conducted within the R environment (R Development Core Team, 2014). Both normality and variance homogeneity were first assessed on all biological and physical 
195

196

197

198

199

200

201

202

203

204

205

206

207

208

209

210

211

212

213

214

215

216

217

218

data sets with Shapiro-Wilk and Bartlett / Levene tests, respectively. Macroalgal community parameters (diversity, indices) were compared between the three sites using Kruskal-Wallis (KW) tests. To establish potential correlations between species and variables Pearson's $r$ coefficients were calculated, using the "corrplot" package (Wei and Wei, 2017). Redundancy analysis (RDA) was carried out with "vegan" (Oksanen et al., 2013) to determine how environmental factors influence the development and the structure of macroalgal communities. Undisturbed sampling or upright profile sampling data were used as response variables and the latitude, for site position, and average wave heights, for hydrodynamics, as explanatory variables. Then, an ANOVA and a constrained ordination were applied to variables of the RDA to determine if the reduced model is significant and, if so, which explanatory variable is mostly involved. Variation of communities was then partitioned with respect to both explanatory variables, i.e. site and wave height. The relative importance of each explanatory variable and their degree of interaction were summarized in Venn diagrams.

\section{Results}

\subsection{Community structure}

Within the sampling period in the three sites, 125 macroalgal species were determined including 15 Chlorophyta, 83 Rhodophyta and 27 Phaeophyceae. Cover of dominating Phaeophyceae, mean species richness and Ics values are given by community and site in Table 1. Cover values of dominating Phaeophyceae ranged between $c a .45 \%$ in $P c$ and $70 \%$ in $A n-F v e s$, with large intra-community and inter-site variations corresponding to the heterogeneity of the intertidal canopies. It is the highest at Porsal for the high and middle intertidal levels and at Porspoder for low intertidal levels (Table 1). Nevertheless, no significant difference was found between sites. Maximum values of macroalgal mean species richness for a spot $\left(\approx 0.33 \mathrm{~m}^{2}\right)$, i.e. 37 species in $L d$ and 34 species in $H e-B b$, were obtained 
in Segal. The mean species richness did not differ significantly between sites for a given community, except for Fspi and $H e-B b$ with higher values at Segal (KW, p-value < 0.05). It increased from the high intertidal zone to the $H e-B b$ community, with a plateau for $L d$. Values of the Shannon-Wiener index ranged between $0.2-3.0$ and those of the R/P ratio varied between 0.5 and 20.0, suggesting large discrepancies in macroalgal diversity between communities (significant differences, KW, p-value $<0.05$ ). However, values did not differ significantly between successive tidal heights $(\mathrm{KW}$, p-value $<0.05)$. The Shannon-Wiener index showed higher values in Segal for the $H e-B b$ community (KW, p-value < 0.05), corresponding to a higher mean species richness (see above). KW tests did not reveal any significant intra-community difference for Ics. Three groups of communities differing significantly (KW, p-value < 0.05) may be observed (Pc and Fspi $\mid$ An - Fves, Fser and He$B b \mid L d$ alone), with increasing values of Ics between these groups.

\subsection{Wave heights}

Wave heights were calculated for each spot and then averaged per community and per site (Table 1), according to the procedure and to the periods defined above. Given that recording periods were different, wave heights were smaller in high level communities than in lower levels and show a reduced variability between sites. Thus, wave heights ranged from 15 to 25 $\mathrm{cm}$ between sites, with an average of $18.90 \pm 6.66 \mathrm{~cm}$, in $P c$ and from 23 to $28 \mathrm{~cm}$, with an average of $24.28 \pm 6.83 \mathrm{~cm}$, in Fspi. In An-Fves, wave heights were greater but show little fluctuation between sites, ranging from $52 \mathrm{~cm}$ to $65 \mathrm{~cm}$, with an average of $58.93 \pm 15.40 \mathrm{~cm}$. For the three lowest communities of the shore, a larger variability occurred in wave heights between sites, i.e. from 94 to $125 \mathrm{~cm}$ in Fser, from 59 to $135 \mathrm{~cm}$ in $\mathrm{He}-\mathrm{Bb}$ and from 45 to 89 $\mathrm{cm}$ in $L d$, with average values per community of $107.16 \pm 21.72 \mathrm{~cm}, 93.04 \pm 35.96 \mathrm{~cm}$ and $72.30 \pm 21.77 \mathrm{~cm}$, respectively. The least exposed site was Porsal, for all communities of the shore, while Segal was the most exposed site for high level communities and Porspoder for 
mid and low intertidal communities. Including all recording periods, the maximum value of wave height obtained in one spot was $158.3 \mathrm{~cm}$, in $\mathrm{He}-\mathrm{Bb}$ at Porspoder, and the minimum is $5.91 \mathrm{~cm}$ in $P c$ at Porsal. Considering the spatial distribution of wave heights inside each community on shorelines up to $250 \mathrm{~m}$, their values may be either randomly distributed or vary significantly with the distance between sampling spots. The most drastic variation observed was a doubling of height values between two neighboring spots in $P c$ at Segal separated only by $8 \mathrm{~m}$, rising from $19 \mathrm{~cm}$ to $37 \mathrm{~cm}$. At the opposite, wave heights may only differ slightly between two spots, like a $12 \%$ discrepancy in $\mathrm{He}-\mathrm{Bb}$ at Porsal, from $\mathrm{ca} .51 \mathrm{~cm}$ to $57 \mathrm{~cm}$, i.e. $6 \mathrm{~cm}$ over $190 \mathrm{~m}$ distance. Wave heights increase towards the open sea in communities with sampling spots placed on an axis perpendicular to the coastline. On the contrary, when the axis parallels the coastline, wave height values were distributed randomly.

\subsection{Effects of hydrodynamics on seaweed communities based on undisturbed sampling}

In order to point out significant factors affecting the structure of seaweed canopies, a redundancy analysis (RDA) was performed for each community. The constrained ordination (p-value < 0.05) on RDA revealed that wave heights influence five out of six macroalgal communities, and that the site had an impact on the highest and the lowest macroalgal communities on the shore (Figure 3).

Wave height variation explained between 9.0 and $15.8 \%$ of the variance for four communities $(P c, A n-F v e s, F s e r, H e-B b)$. By contrast, site effects never explained more than $2 \%$ of the variance and may be considered as negligible. The interaction between wave height and site had also a small impact for most of the communities, except $P c$ and $L d$. For $L d$, the contribution of each physical variables was difficult to determine. No significant result was evidenced for the Fspi community, suggesting no effect of site nor wave height on the community structure. 
To assess the effect of hydrodynamics in community structure, correlation tests were applied between wave heights and undisturbed cover data, results shown in Figure 4. Cover of several dominating Fucales was negatively correlated with wave heights. The highest correlation $(r=$ -0.54) was observed for the $P c$ community, whereas correlation coefficients were between 0.39 and -0.48 for mid-to-low intertidal communities. Other Fucales did not show any correlation, like $F$. spiralis with a p-value of 0.84 in its own community, $F$. vesiculosus with $p$-value $=0.39$ in An-Fves and $H$. elongata with a $p$-value of 0.05 in $H e-B b$. Two opposite cases were observed with Laminariales structuring the lowest levels ( $L d$ community), a positive correlation with wave heights for L. digitata $(r=0.39)$, but a negative one with $S$. latissima $(r=-0.36)$. A positive correlation was also observed between wave heights and the total cover of erect Rhodophyta in the An - Fves community $(r=0.37)$ and in $\mathrm{He}-\mathrm{Bb}(r=$ 0.39), and a negative correlation with the cover of $H$. elongata in the $L d$ community ( $r=-$ $0.44)$.

\subsection{Effects of hydrodynamics on seaweed communities based on upright profile sampling}

Following the same method used for undisturbed sampling, a RDA was conducted on the covering of all seaweed species. Wave height had an impact on four communities, while the site factor affects significantly five communities (Figure 5). The variation of the two explanatory variables partly diverged from the results obtained in the case of the undisturbed sampling. The range of variation due to wave heights was larger, between 3.6 and $19.1 \%$. The site effect was globally higher and varies between 4.1 and $17.4 \%$. Unlike the undisturbed sampling, the Fspi community showed a significant response, whereas $A n-F v e s$ did not.

Correlation coefficients were calculated for all seaweed species and for various biological indices relative to wave heights. Results are summarized in Table 1. The same tendencies were found in both upright profile and undisturbed samplings for the cover of $P$. canaliculata 
in $P c, B$. bifurcata in $H e-B b, L$. digitata and H. elongata in $L d$, with similar correlation values (Figure 6). In contrast, no correlation was found with any Fucales in An - Fves and in Fser.

Considering Chlorophyceae, a negative correlation was evidenced in An-Fves and in Fser between the cover of Cladophora rupestris and wave heights, with coefficients of -0.46 and 0.36 respectively.

The cover of several erect Rhodophyta appeared to be dependent on wave heights. At intermediate intertidal levels, Chondracanthus acicularis and Gelidium spinosum were positively correlated with hydrodynamics with Pearson's $r$ of 0.44 and 0.35 , respectively. A similar result was obtained in $\mathrm{He}-\mathrm{Bb}$ for $\mathrm{G}$. spinosum $(r=0.62)$, Ellisolandia (Corallina) elongata $(r=0.40)$, Chondrus crispus $(r=0.39)$, Gelidium corneum $(r=0.35)$ and Ceramium $\operatorname{virgatum}(r=0.33)$.

Mean species richness and Shannon index did not correlate with wave heights. However, the Ics index showed negative correlations at the community level in $P c(r=-0.42)$ and Fser $(r=$ -0.39). In low levels of the shore, correlations were evidenced for the $\mathrm{R} / \mathrm{P}$ ratio, positive in $\mathrm{He}$ $-B b(r=0.41)$ and negative in $L d(r=-0.38)$.

\section{Discussion}

Although the existence of a relationship between wave exposure and rocky intertidal assemblages has been described for a long time (Little and Kitching, 1996), few studies have addressed this issue beyond the clear contrast opposing sheltered, seaweed-covered shores, to exposed, less-vegetated ones (e.g. Cabioc'h et al., 2014). The variability of wave exposure occurring within a shore and its potential impact on inducing small-scale (at the metric scale) variability in intertidal habitats (e.g. O'Donnell and Denny, 2008) are often overlooked in the literature. Our study addressed this paradigm on six different macroalgal communities 
distributed vertically on rocky shores of the Western Brittany coastline, using in situ highfrequency direct monitoring of wave exposure. Therefore, this work provides insights about this important aspect of intertidal ecology.

Correlations between dominating Phaeophyceae and wave height nearly show the same patterns for undisturbed and upright profile samplings suggesting that both approaches are pertinent to evaluate the effects of hydrodynamics on macroalgal communities. Thus, negative correlations occur between the cover of several dominating Fucales and wave height following both procedures. This result is in agreement with the statement that tearing off macroalgae by strong hydrodynamics make canopies regress drastically (Ballantine, 1961; Lewis, 1964; Burrows et al., 2008). As shown in other works (Grenager and Baardseth, 1965), cover regression affects particularly dominating Phaeophyceae, except for $L$. digitata which is favored by an increase of wave exposure. In sheltered locations, important sediment deposit may occur (Ballantine, 1961), limiting the development of large, perennial macroalgae to the benefit of short-lived opportunistic macroalgae (Daly and Mathieson, 1977). L. digitata, for instance, does not withstand a long burying of its large holdfast under sediments (Ar Gall et al., 2016). In that way, in low wave exposure, L. digitata may be replaced relatively quickly by S. latissima which is more efficient in colonizing unstable substrata (Bunker et al., 2017). Furthermore, L. digitata shows higher growth rates in relatively agitated water (Kregting et al., 2016). Consequently, the fact that the $L d$ community exhibits a positive correlation between wave heights and cover of L. digitata is not surprising and in agreement with studies on hydrodynamic tolerant kelps (Starko and Martone, 2016). The lack of correlation between wave height and the cover of dominating species in Fspi might be related to a heatwave in summer 2016 which resulted in a decrease of $F$. spiralis cover by nearly $70 \%$ at Porspoder (pers. obs.). The size of H. elongata follows high seasonal variations, with the elongation of receptacles up to four meters in Spring and their falling down in Autumn (Cabioc'h et al., 
2014). Such a high seasonality might account for the lack of correlation observed between the cover of that co-dominating species and wave heights in $\mathrm{He}-\mathrm{Bb}$.

The mean species richness may be a good tool to evaluate the ecological state of a seaweed community (Wells et al., 2007) and was occasionally related to hydrodynamics (Nishihara and Terada, 2010). Although they did not reveal any correlation between macroalgal diversity and hydrodynamics, our results remain consistent with those of Connan (2004) and Ar Gall and Le Duff (2014). Ics values found in this study are similar to those reported by Ar Gall and Le Duff (2014) in all communities. However, in the low shore of Porspoder, Ics scores of $\mathrm{He}$ $-B b$ and $L d$ communities are clearly higher (beyond the standard deviation). Besides, other monitoring results from the Rebent (Benthic Network in Brittany) has already shown values exceeding 1.32 for $H e-B b$ in seven sites and 1.52 for $L d$ at three sites (Ar Gall and Le Duff, pers. comm.). This descriptive index is negatively correlated to hydrodynamics in $P c$ and Fser with no significant relationship in other communities, pointing out an irregular effect of waves and swell on both the extension and the structure of macroalgal communities. The absence of a correlation between hydrodynamics and Shannon-Wiener index is probably related to the large dispersion of values. At the opposite, the R/P ratio is positively correlated to wave height in $\mathrm{He}-\mathrm{Bb}$ and negatively in $L d$, showing that hydrodynamics promotes the predominance of Rhodophyta in $H e-B b$, while it favors Phaeophyceaen species in $L d$.

The variance partitioning shows that hydrodynamics has an effect on most of the studied communities explaining up to $15.8 \%$ of the total variance in undisturbed sampling and $19.1 \%$ in upright profile sampling. These values are high when considering a single explanatory variable in variance partitioning (e.g. Quillien et al., 2015). They tend to confirm the major role of hydrodynamics on intertidal assemblages at local scale (Cefalì et al., 2016).

Differences were evidenced between the two sampling approaches when comparing Venn diagrams. Undisturbed sampling is mainly influenced by wave heights, whereas upright 
profile sampling is also affected by the site explanatory variable. This discrepancy is stronger in the low intertidal zone, with more contrasted positive and negative correlations with hydrodynamics. While undisturbed sampling only detects variations in the cover of canopy forming Phaeophyceae, upright profile sampling gives also information on the effect of wave exposure on understory species. For instance, positive correlations between wave height and epilithic turf-forming species like Chondrus crispus, Gelidium spinosum and G. corneum reflect the fact that Rhodophytes better withstand hydrodynamics thanks to an overall smaller size than large Phaeophyta in the intertidal zone (Puente et al., 2016). Increasing cover of red seaweeds may also explain partially the concomitant regression of large Fucales such as $F$. serratus and A. nodosum, suggesting a competition between these two functional groups. Increasing covers due to stronger hydrodynamics is documented so far in the genus Gelidium (Prathep et al., 2009). In the same way, a positive correlation with hydrodynamics is observed for Ellisolandia (Corallina) elongata, a finding already reported from the North of Spain where Corallina spp. dominate intertidal communities (Ramos et al., 2016a). Indeed, the thallus organization of articulate coralline seaweeds is considered as well adapted to exposed biotopes (Martone and Denny, 2008). In the case of Ceramium virgatum, mostly growing as epiphyte on other species (Maggs and Hommersand, 1993), the positive correlation may be associated to the physical damages caused by hydrodynamics to host species, either directly by wave action, or indirectly by grazing, which both favor the development of epiphytes (Gaylord, 1999). An indirect relationship between Cladophora rupestris and hydrodynamics may be suspected, since this species grows preferentially under the canopies of Fucus spp. and A. nodosum (Brodie et al., 2007), as underlined in our study by a strong correlation with the cover of Fucales ( $r=0.68$ in Fser and $r=0.61$ in An-Fves).

Wave heights inside a community may vary randomly or follow a coastline - open sea gradient, depending on the distribution of the sampling spots. Wave heights averaged on three 
391

392

393

394

395

396

397

398

399

400

401

402

403

404

405

406

407

408

409

410

411

412

413

414

415

sites vary between $c a .19 \mathrm{~cm}$ in $P c$ and $c a .108 \mathrm{~cm}$ in Fser with maximal values reaching around $160 \mathrm{~cm}$. The data presented in our study are consistent with those from previous studies for assemblages dominated by sessile animals and limpets obtained by in situ wave height recording (O'Donnell and Denny, 2008) or by buoy sensors (Gilman et al., 2006). However, values are rather low compared to those reported from previous works (e.g. Jones and Demetropoulos, 1968; Bell and Denny, 1994), probably because these recordings are oneoff measurements. Wave heights differ between communities and so between corresponding altitudes on the shore, but no statement can be inferred from these data, given that recording periods are different. To carry out an inter-community study of hydrodynamics, it would be necessary to monitor pressures simultaneously on a single site. Discrepancies in wave heights occur also between sites for a single community, a result which may be linked to surrounding topography and site openness. For example, Porsal is the least exposed site, probably due to the occurrence of numerous reefs off the coast (more than 30 islets permanently emerged in all directions within a radius of $4 \mathrm{~km}$ from the site).

Even though all wave oscillations (usual periods between $6 \mathrm{~s}$ and $12 \mathrm{~s}$, versus $25 \mathrm{~s}$ in our study) could not be taken into account in our in situ monitoring of hydrodynamics, data obtained by Mini-Diver® sensors at a frequency of $0.04 \mathrm{~Hz}(\mathrm{~T}=25 \mathrm{~s})$ are coherent with significant wave heights calculated from values obtained at a frequency of $1 \mathrm{~Hz}(\mathrm{~T}=1 \mathrm{~s})$ (unpublished personal data), measured by the same sensors within shorter durations (e.g. $6 \mathrm{~h}$ versus $c a .7$ days) and by Wave Gauge OSSI-010-003C-03 sensor (Ocean Sensor Systems Inc., Coral Springs, USA). Considering the one-week period used to evaluate wave height exposure, structural differences observed in a given macroalgal community depend on the hydrodynamic forces conditioning it all year long (Levin and Paine, 1974; Ramos et al., 2016b). Thus, the spatial study of community structure, relatively to a condensed set of wave exposure data (here wave heights), may be informative enough about the long-term effect of 
hydrodynamics. The coherence of the following results suggests the temporal representativeness of our wave height data: (1) when sampling spots are distributed along a coastline -open sea transect, wave height values follow a corresponding increasing gradient (2) sampling spots are numerous enough to consider the micro-topography of the shore at the intra-community level (3) the average wave height follows site patterns per community.

Considering the above assertions, wave height may be considered as an adequate descriptor/proxy of local hydrodynamics. In the same way, the small-scale monitoring performed in this study is efficient to characterize the hydrodynamics at the community level. However, further experiments should be scheduled to assess the accuracy of our experimental approach with longer time hydrodynamic regimes ( $c f$. Guillou and Chapalain, 2015). Finally, it would be interesting to compare the trends delineated at the assemblage level by our local scale wave height proxy to larger scale approaches at the site level, such as fetch measurements or Baardseth index (Baardseth, 1970; Burrows et al., 2008).

The originality of the ecological evaluation of seaweed assemblages carried out in this study lies in (1) the community approach(Ar Gall et al., 2016) (2) the fine space scale used to assess hydrodynamics (3) the double (undisturbed and upright profile) sampling analysis. Although the zonation of communities is well described in the world (Lüning, 1990; Barnes and Hughes, 1999; Witman and Roy, 2009), and the contribution of hydrodynamics to the differentiation of seaweed canopies has been partially investigated, an inter-community study of wave exposure at the site level has still to be achieved. In this prospect, the intracommunity procedure developed in this work may constitute an efficient approach.

\section{Acknowledgments}

We thank Antoine Douchin for data comparison between Mini-Diver® and Wave Gauge OSSI-010-003C-03 sensors. We also thank Sarah Beauvais, Valentin Lagarde and JeanBaptiste Valerdi for helping at field sampling. This work benefited from the experience 
gained during the Rebent (funded by the Brittany Regional Council and the DREAL at

Rennes) and the WFD (Ifremer, Agence de l'Eau Loire - Bretagne, Agence Française de la

laboratory Lemar UMR6539.

\section{Bibliography}

Abbott, I.A., Hollenberg, G.J., 1976. Marine algae of California. Stanford University Press, Standford, CA, USA, p. 827 pp.

Ar Gall, E., Le Duff, M., 2014. Development of a quality index to evaluate the structure of macroalgal communities. Estuarine, Coastal and Shelf Science 139, 99-109.

Ar Gall, E., Le Duff, M., Sauriau, P.G., de Casamajor, M.N., Gevaert, F., Poisson, E., Hacquebart, P., Joncourt, Y., Barillé, A.L., Buchet, R., Bréret, M., Miossec, L., 2016. Implementation of a new index to assess intertidal seaweed communities as bioindicators for the European Water Framework Directory. Ecological Indicators 60, 162-173.

Autret, R., Dodet, G., Fichaut, B., Suanez, S., David, L., Leckler, F., Ardhuin, F., Ammann, J., Grandjean, P., Allemand, P., Filipot, J.-F., 2016. A comprehensive hydro-geomorphic study of cliff-top storm deposits on Banneg Island during winter 2013-2014. Marine Geology 382, 37-55.

Baardseth, E., 1970. A square scanning, two stage sampling method of estimating seaweed quantities. Rep Norw Inst Seaweed Res 33, 1-41.

Ballantine, W.J., 1961. A biologically-defined exposure scale for the comparative description of rocky shores. Field Studies Journal 1, 1-19.

Balliston, N.E., McCarter, C.P.R., Price, J.S., 2018. Microtopographical and hydrophysical controls on subsurface flow and solute transport: A continuous solute release experiment in a subarctic bog. Hydrological Processes 32, 2963-2975.

Barnes, R.S.K., Hughes, R.N., 1999. An introduction to marine ecology. John Wiley \& Sons, p. 296 pp. Bell, E.C., Denny, M.W., 1994. Quantifying "wave exposure": a simple device for recording maximum velocity and results of its use at several field sites. Journal of Experimental Marine Biology and Ecology 181, 9-29.

Bird, C.E., Franklin, E.C., Smith, C.M., Toonen, R.J., 2013. Between tide and wave marks: a unifying model of physical zonation on littoral shores. PeerJ 1, e154.

Boaventura, D.M., 2000. Patterns of distribution in intertidal rocky shores: the role of grazing and competition in structuring communities. University of Faro, $149 \mathrm{pp}$.

Brodie, J., Maggs, C.A., John, D.M., Blomster, J., 2007. Green seaweeds of Britain and Ireland. British Phycological Society, p. 250 pp.

Bunker, F., Brodie, J., Maggs, C., Bunker, A., 2017. Seaweeds of Britain and Ireland. Wild Nature Press Plymouth, UK, p. 312 pp.

Burrows, M.T., Harvey, R., Robb, L., 2008. Wave exposure indices from digital coastlines and the prediction of rocky shore community structure. Marine Ecology Progress Series 353, 1-12. Cabioc'h, J., Floc'h, J.-Y., Le Toquin, A., Boudouresque, C.F., Meinesz, A., Verlaque, M., 2014. Algues des mers d'Europe. Delachaux et Niestlé, p. 272 pp.

Camus, P., Mendez, F.J., Medina, R., Tomas, A., Izaguirre, C., 2013. High resolution downscaled ocean waves (DOW) reanalysis in coastal areas. Coastal Engineering 72, 56-68.

Cefalì, M.E., Cebrian, E., Chappuis, E., Pinedo, S., Terradas, M., Mariani, S., Ballesteros, E., 2016. Life on the boundary: Environmental factors as drivers of habitat distribution in the littoral zone. Estuarine, Coastal and Shelf Science 172, 81-92. 
Connan, S., 2004. Etude de la diversité spécifique des macroalgues de la Pointe de Bretagne et analyse des composés phénoliques des Phéophycées dominantes. University of Brest, 280 pp. Dahlhoff, E.P., 2004. Biochemical Indicators of Stress and Metabolism: Applications for Marine Ecological Studies. Annual Review of Physiology 66, 183-207.

Daly, M., Mathieson, A., 1977. The effects of sand movement on intertidal seaweeds and selected invertebrates at Bound Rock, New Hampshire, USA. Marine Biology 43, 45-55.

Denny, M.W., 2006. Ocean waves, nearshore ecology, and natural selection. Aquatic Ecology 40, 439461.

Denny, M.W., Wethey, D.S., 2001. Physical processes that generate patterns in marine communities, in: Bertness, M.D., Gaines, S.D., Hay, M.E. (Eds.), Marine Community Ecology. Sinauer, Sunderland, Massachusetts, USA, pp. 3-37.

Floc'h, J.Y., 1964. Distribution verticale et écologie des algues marines sur les côtes bretonnes. Penn Ar Bed 4, 182-190.

Gaylord, B., 1999. Detailing agents of physical disturbance: wave-induced velocities and accelerations on a rocky shore. Journal of Experimental Marine Biology and Ecology 239, 85-124.

Gaylord, B., Blanchette, C.A., Denny, M.W., 1994. Mechanical Consequences of Size in Wave-Swept Algae. Ecological Monographs 64, 287-313.

Gilman, S.E., Harley, C.D.G., Strickland, D.C., Vanderstraeten, O., O'Donnell, M.J., Helmuth, B., 2006. Evaluation of effective shore level as a method of characterizing intertidal wave exposure regimes. Limnology and Oceanography: Methods 4, 448-457.

Grenager, B., Baardseth, E., 1965. A two-stage sampling method of estimating seaweed quantities, Proceedings of the 5th International Seaweed Symposium, pp. 129-135.

Guillou, N., Chapalain, G., 2015. Numerical modelling of nearshore wave energy resource in the Sea of Iroise. Renewable Energy 83, 942-953.

Helmuth, B., Denny, M.W., 2003. Predicting wave exposure in the rocky intertidal zone: Do bigger waves always lead to larger forces? Limnology and Oceanography 48, 1338-1345.

Holthuijsen, L.H., 2010. Waves in oceanic and coastal waters. Cambridge University Press, p. 387 pp. Jones, W.E., Demetropoulos, A., 1968. Exposure to wave action: Measurements of an important ecological parameter on rocky shores on Anglesey. Journal of Experimental Marine Biology and Ecology 2, 46-63.

Kregting, L., Blight, A.J., Elsäßer, B., Savidge, G., 2016. The influence of water motion on the growth rate of the kelp Laminaria digitata. Journal of Experimental Marine Biology and Ecology 478, 86-95. Le Hir, M., Hily, C., 2005. Macrofaunal diversity and habitat structure in intertidal boulder fields. Biodiversity \& Conservation 14, 233.

Levin, S.A., Paine, R.T., 1974. Disturbance, Patch Formation, and Community Structure. Proceedings of the National Academy of Sciences 71, 2744-2747.

Lewis, J.R., 1964. The Ecology of Rocky Shores. English University Press, London, p. 323 pp. Little, C., Kitching, J.A., 1996. The biology of rocky shores. Oxford University Press, USA, p. 240 pp. Lüning, K., 1990. Seaweeds: their environment, biogeography, and ecophysiology. John Wiley \& Sons, p. 527 pp.

Maggs, C., Hommersand, M.H., 1993. Seaweeds of the British Isles. Volume 1 Rhodophyta, Part 3A Ceramiales, p. 444 pp.

Martone, P.T., Denny, M.W., 2008. To break a coralline: mechanical constraints on the size and survival of a wave-swept seaweed. Journal of Experimental Biology 211, 3433-3441.

Menge, B.A., Branch, G.M., 2001. Rocky Intertidal Communities, in: Bertness, M.D., Gaines, S.D., Hay, M.E. (Eds.), Marine Community Ecology. Sinauer, Sunderland, Massachusetts, USA, pp. 221-251. Mieszkowska, N., Milligan, G., Burrows, M.T., Freckleton, R., Spencer, M., 2013. Dynamic species distribution models from categorical survey data. Journal of Animal Ecology 82, 1215-1226. Munda, I.M., 1978. Survey of the benthic algal vegetation of the Dýrafjördur, Northwest Iceland. Nova Hedwigia 29, pp. 281-403.

Nishihara, G.N., Terada, R., 2010. Species richness of marine macrophytes is correlated to a wave exposure gradient. Phycological Research 58, 280-292. 
O'Connor, N.E., Donohue, I., Crowe, T.P., Emmerson, M.C., 2011. Importance of consumers on exposed and sheltered rocky shores. Marine Ecology Progress Series 443, 65-75.

O'Donnell, M.J., Denny, M.W., 2008. Hydrodynamic forces and surface topography: Centimeter-scale spatial variation in wave forces. Limnology and Oceanography 53, 579-588.

Oksanen, J., Blanchet, F.G., Kindt, R., Legendre, P., Minchin, P.R., O’hara, R., Simpson, G.L., Solymos, P., Stevens, M.H.H., Wagner, H., 2013. Package 'vegan'. Community ecology package, version 2. Paine, R.T., 1966. Food Web Complexity and Species Diversity. The American Naturalist 100, 65-75. Paine, R.T., Levin, S.A., 1981. Intertidal Landscapes: Disturbance and the Dynamics of Pattern. Ecological Monographs 51, 145-178.

Prathep, A., Lewmanomont, K., Buapet, P., 2009. Effects of wave exposure on population and reproductive phenology of an algal turf, Gelidium pusillum (Gelidales, Rhodophyta), Songkhla, Thailand. Aquatic Botany 90, 179-183.

Puente, A., Guinda, X., Juanes, J.A., Ramos, E., Echavarri-Erasun, B., De La Hoz, C.F., Degraer, S., Kerckhof, F., Bojanić, N., Rousou, M., Orav-Kotta, H., Kotta, J., Jourde, J., Pedrotti, M.L., Leclerc, J.-C., Simon, N., Bachelet, G., Lavesque, N., Arvanitidis, C., Pavloudi, C., Faulwetter, S., Crowe, T.P., Coughlan, J., Cecchi, L.B., Dal Bello, M., Magni, P., Como, S., Coppa, S., De Lucia, G.A., Rugins, T., Jankowska, E., Weslawski, J.M., Warzocha, J., Silva, T., Ribeiro, P., De Matos, V., Sousa-Pinto, I., Troncoso, J., Peleg, O., Rilov, G., Espinosa, F., Ruzafa, A.P., Frost, M., Hummel, H., Van Avesaath, P., 2016. The role of physical variables in biodiversity patterns of intertidal macroalgae along European coasts. Journal of the Marine Biological Association of the United Kingdom 97, 549-560.

Quillien, N., Nordström, M.C., Gauthier, O., Bonsdorff, E., Paulet, Y.-M., Grall, J., 2015. Effects of macroalgal accumulations on the variability in zoobenthos of high-energy macrotidal sandy beaches. Marine Ecology Progress Series 522, 97-114.

R Development Core Team, 2014. R: A Language and Environment for Statistical Computing. Vienna: R Foundation for Statistical Computing. , Available at : www. R-project. org. Raffaelli, D.G., Hawkins, S.J., 1999. Intertidal ecology, 2 ed, Dordrecht, p. 356 pp. Ramos, E., Díaz de Terán, J.R., Puente, A., Juanes, J.A., 2016a. The role of geomorphology in the distribution of intertidal rocky macroalgae in the NE Atlantic region. Estuarine, Coastal and Shelf Science 179, 90-98.

Ramos, E., Puente, A., Juanes, J.A., 2016b. An ecological classification of rocky shores at a regional scale: a predictive tool for management of conservation values. Marine Ecology 37, 311-328.

Rattray, A., lerodiaconou, D., Womersley, T., 2015. Wave exposure as a predictor of benthic habitat distribution on high energy temperate reefs. Frontiers in Marine Science 2, 1-14.

Reguero, B.G., Menéndez, M., Méndez, F.J., Mínguez, R., Losada, I.J., 2012. A Global Ocean Wave (GOW) calibrated reanalysis from 1948 onwards. Coastal Engineering 65, 38-55.

Starko, S., Martone, P.T., 2016. Evidence of an evolutionary-developmental trade-off between drag avoidance and tolerance strategies in wave-swept intertidal kelps (Laminariales, Phaeophyceae). Journal of Phycology 52, 54-63.

Stephenson, T., Stephenson, A., 1949. The universal features of zonation between tide-marks on rocky coasts. The Journal of Ecology, 289-305.

Suanez, S., Stéphan, P., Floc'h, F., Autret, R., Fichaut, B., Blaise, E., Houron, J., Ammann, J., Grandjean, P., Accensi, M., 2019. Fifteen years of hydrodynamic forcing and morphological changes leading to breaching of a gravel spit, Sillon de Talbert (Brittany). Géomorphologie: relief, processus, environnement 24, 403-428.

R Development Core Team, 2014. R: A Language and Environment for Statistical Computing. Vienna: R Foundation for Statistical Computing. , Available at : www. R-project. org. Thomas, M.L.H., 1986. A physically derived exposure index for marine shorelines. Ophelia 25, 1-13. Van Putte, N., Temmerman, S., Verreydt, G., Seuntjens, P., Maris, T., Heyndrickx, M., Boone, M., Joris, I., Meire, P., 2019. Groundwater dynamics in a restored tidal marsh are limited by historical soil compaction. Estuarine, Coastal and Shelf Science.

Want, A., Beharie, R.A., Bell, M.C., Side, J.C., 2014. Baselines and Monitoring Methods for Detecting Impacts of Hydrodynamic Energy Extraction on Intertidal Communities of Rocky Shores, in: Shields, 
590 M.A., Payne, A.I.L. (Eds.), Marine Renewable Energy Technology and Environmental Interactions.

591 Springer Netherlands, Dordrecht, pp. 21-38.

592 Wei, T., Wei, M.T., 2017. Package 'corrplot'. Statistician 56, 316-324.

593 Wells, E., Wilkinson, M., Wood, P., Scanlan, C., 2007. The use of macroalgal species richness and

594 composition on intertidal rocky seashores in the assessment of ecological quality under the European

595 Water Framework Directive. Marine Pollution Bulletin 55, 151-161.

596 Witman, J.D., Roy, K., 2009. Marine macroecology. University of Chicago Press, p. 424 pp.

597 Wolcott, B.D., 2007. Mechanical size limitation and life-history strategy of an intertidal seaweed.

598 Marine Ecology Progress Series 338, 1-10.

599 
Table 1: Average values and standard deviations of Ics, mean species richness, cover of

601 dominating Phaeophyceae, average wave heights corresponding recording periods per

602 community and site. Communities dominated by: $P c=$ Pelvetia canaliculata, Fspi $=$ Fucus

603 spiralis, An-Fves = Ascophyllum nodosum - Fucus vesiculosus, Fser $=$ Fucus serratus, He

$604-B b=$ Himanthalia elongata - Bifurcaria bifurcata, Ld = Laminaria digitata .

\begin{tabular}{|c|c|c|c|c|c|c|c|}
\hline $\begin{array}{c}\text { Intertidal } \\
\text { level }\end{array}$ & Community & Site & Ics & $\begin{array}{l}\text { Mean } \\
\text { species } \\
\text { richness }\end{array}$ & $\begin{array}{c}\% \text { cover of } \\
\text { dominating } \\
\text { Phaeophycean }\end{array}$ & $\begin{array}{l}\text { Average wave } \\
\text { height }(\mathrm{cm})\end{array}$ & $\begin{array}{c}\text { Wave height } \\
\text { / seaweed } \\
\text { sampling } \\
\text { period }\end{array}$ \\
\hline \multirow{6}{*}{ High } & \multirow{3}{*}{$P c$} & Segal & $\begin{array}{c}0.56 \pm \\
0.23\end{array}$ & $5.08 \pm 1.24$ & $38.13 \pm 21.75$ & $24.96 \pm 4.91$ & \multirow{3}{*}{$\begin{array}{l}08 / 05 / 17 \text { to } \\
14 / 05 / 17\end{array}$} \\
\hline & & Porspoder & $\begin{array}{c}0.57 \pm \\
0.15\end{array}$ & $4.17 \pm 1.03$ & $39.38 \pm 24.52$ & $16.16 \pm 3.41$ & \\
\hline & & Porsal & $\begin{array}{c}0.56 \pm \\
0.16\end{array}$ & $4.58 \pm 1.16$ & $54.17 \pm 33.63$ & $15.56 \pm 6.72$ & \\
\hline & \multirow{3}{*}{ Fspi } & Segal & $\begin{array}{c}0.86 \pm \\
0.24\end{array}$ & $13.17 \pm 5.10$ & $60.21 \pm 30.22$ & $27.61 \pm 5.21$ & \multirow{3}{*}{$\begin{array}{l}15 / 02 / 17 \text { to } \\
22 / 02 / 17\end{array}$} \\
\hline & & Porspoder & $\begin{array}{c}0.73 \pm \\
0.25\end{array}$ & $7.83 \pm 4.45$ & $41.45 \pm 27.02$ & $23.82 \pm 4.88$ & \\
\hline & & Porsal & $\begin{array}{c}0.87 \pm \\
0.18\end{array}$ & $92 \pm 2.02$ & $60.83 \pm 31.34$ & $23.54 \pm 9.11$ & \\
\hline \multirow{6}{*}{ Medium } & \multirow{3}{*}{ An-Fves } & Segal & $\begin{array}{c}1.12 \pm \\
0.30\end{array}$ & $13.75 \pm 6.73$ & $61.04 \pm 34.70$ & $59.91 \pm 8.52$ & \multirow{3}{*}{$\begin{array}{l}12 / 01 / 17 \text { to } \\
19 / 01 / 17\end{array}$} \\
\hline & & Porspode & $\begin{array}{c}1.07 \pm \\
0.28\end{array}$ & $13.17 \pm 3.93$ & $75.00 \pm 33.51$ & $64.23 \pm 20.96$ & \\
\hline & & Porsal & $\begin{array}{c}1.03 \pm \\
0.52\end{array}$ & $12.17 \pm 3.90$ & $76.04 \pm 26.23$ & $52.64 \pm 12.95$ & \\
\hline & \multirow{3}{*}{ Fser } & Segal & $\begin{array}{c}1.13 \pm \\
0.23\end{array}$ & $19.25 \pm 4.67$ & $45.42 \pm 27.11$ & $102.04 \pm 9.63$ & \multirow{3}{*}{$\begin{array}{c}01 / 02 / 17 \text { to } \\
08 / 02 / 17\end{array}$} \\
\hline & & Porspoder & $\begin{array}{c}0.95 \pm \\
0.29\end{array}$ & $14.42 \pm 5.99$ & $45.00 \pm 34.79$ & $124.66 \pm 29.38$ & \\
\hline & & Porsal & $\begin{array}{c}0.96 \pm \\
0.25\end{array}$ & $15.75 \pm 3.96$ & $55.21 \pm 25.88$ & $94.77 \pm 3.81$ & \\
\hline \multirow[t]{2}{*}{ Low } & \multirow[t]{2}{*}{$H e-B b$} & Segal & $\begin{array}{c}1.15 \pm \\
0.27\end{array}$ & $30.17 \pm 3.71$ & $41.46 \pm 32.64$ & $84.93 \pm 24.61$ & \multirow{2}{*}{$\begin{array}{c}15 / 03 / 17 \text { to } \\
22 / 03 / 17\end{array}$} \\
\hline & & Porspoder & $1.32 \pm$ & $22.83 \pm 3.66$ & $57.08 \pm 21.50$ & $134.7 \pm 17.45$ & \\
\hline
\end{tabular}




\begin{tabular}{|c|c|c|c|c|c|c|}
\hline & \multicolumn{5}{|c|}{0.16} & \\
\hline & Porsal & $\begin{array}{c}1.07 \pm \\
0.14\end{array}$ & $23.25 \pm 3.28$ & $52.71 \pm 29.30$ & $59.50 \pm 3.61$ & \\
\hline \multirow{3}{*}{$L d$} & Segal & $\begin{array}{c}1.42 \pm \\
0.19\end{array}$ & $25.58 \pm 6.24$ & $57.82 \pm 21.02$ & $84.10 \pm 13.29$ & \multirow{3}{*}{$\begin{array}{c}31 / 03 / 17 \text { to } \\
07 / 04 / 17\end{array}$} \\
\hline & Porspoder & $\begin{array}{c}1.52 \pm \\
0.17\end{array}$ & $21.82 \pm 7.39$ & $78.18 \pm 16.92$ & $88.72 \pm 8.96$ & \\
\hline & Porsal & $\begin{array}{c}1.42 \pm \\
0.19\end{array}$ & $24.17 \pm 4.41$ & $69.79 \pm 20.79$ & $45.44 \pm 2.78$ & \\
\hline
\end{tabular}




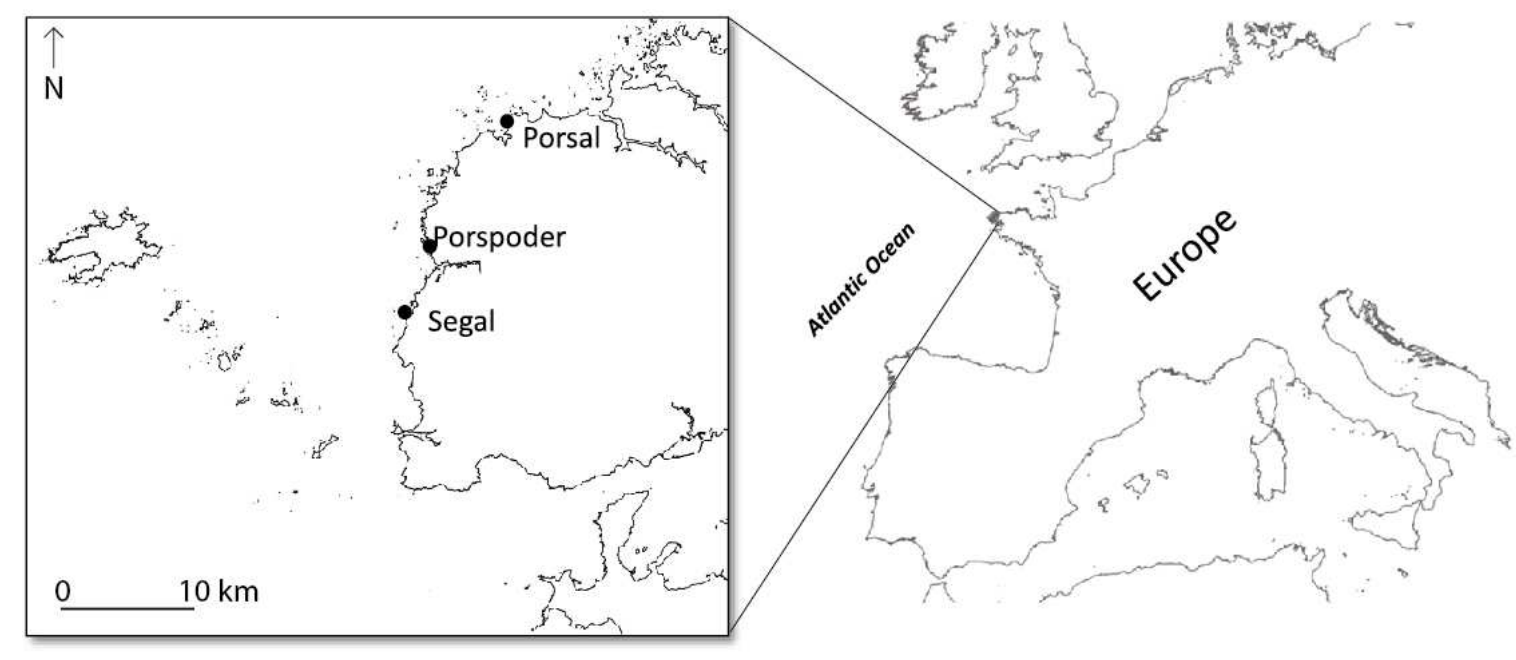

606

Figure 1: Location of the three sites on the North-West coast of Brittany 


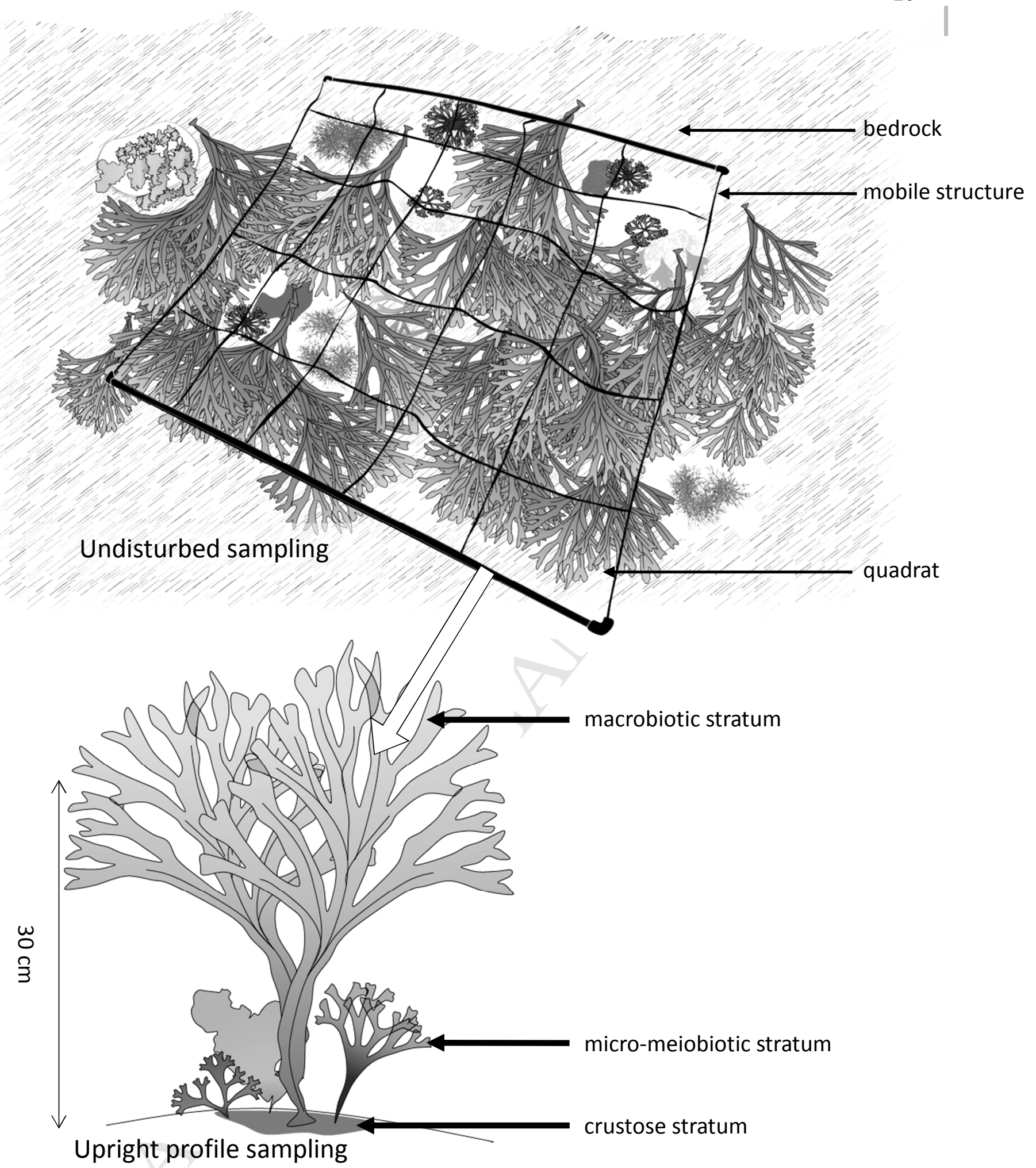

612 Figure 2: Description of the two methods of sampling used in the study. Undisturbed

613 sampling takes into account the major groups of macrophytes on the whole structure. upright 614 profilesampling is based on a finer description of the macrophytes species and their canopy 615 and is applied in three quadrats of the structure. 
616

617

Undisturbed sampling

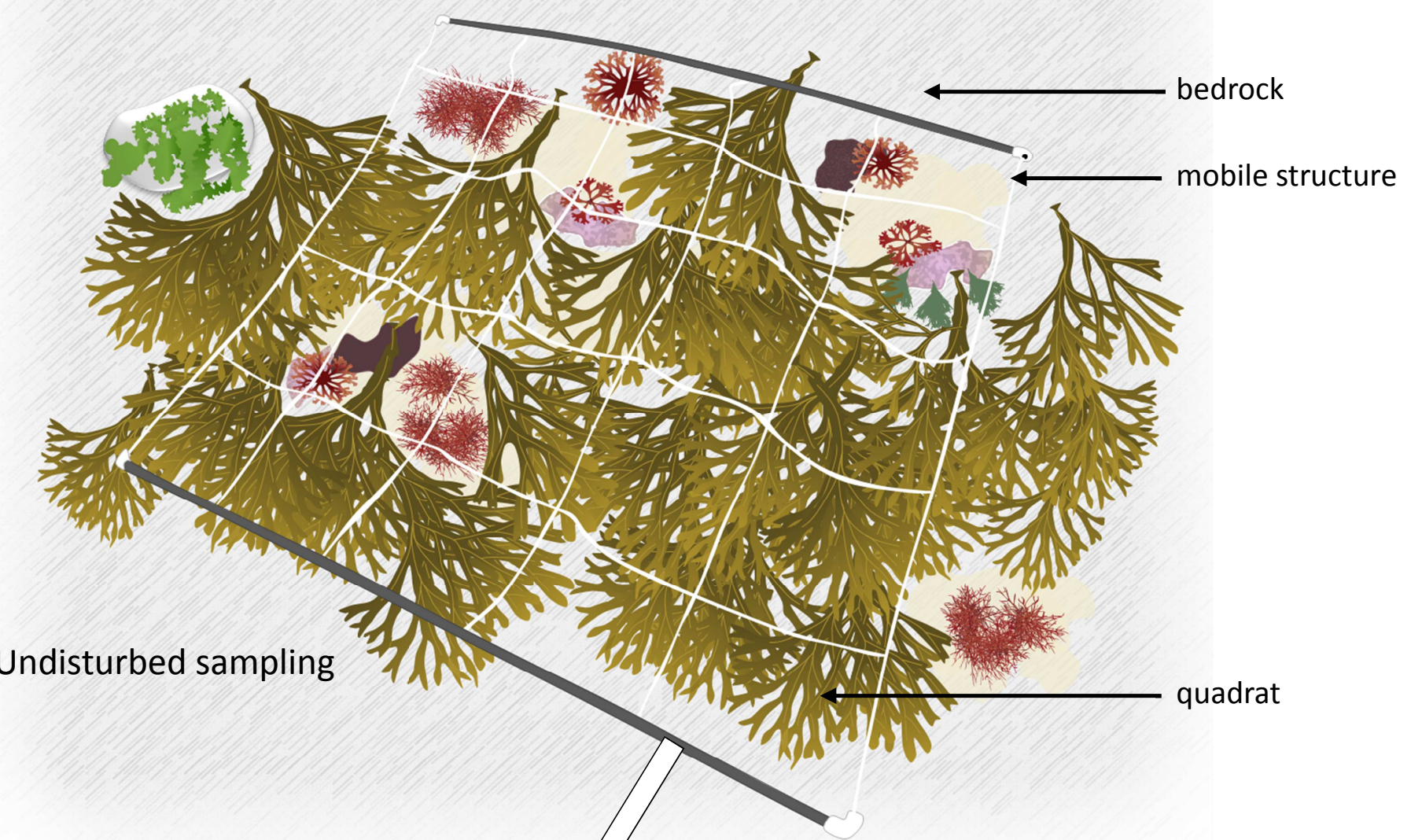

618

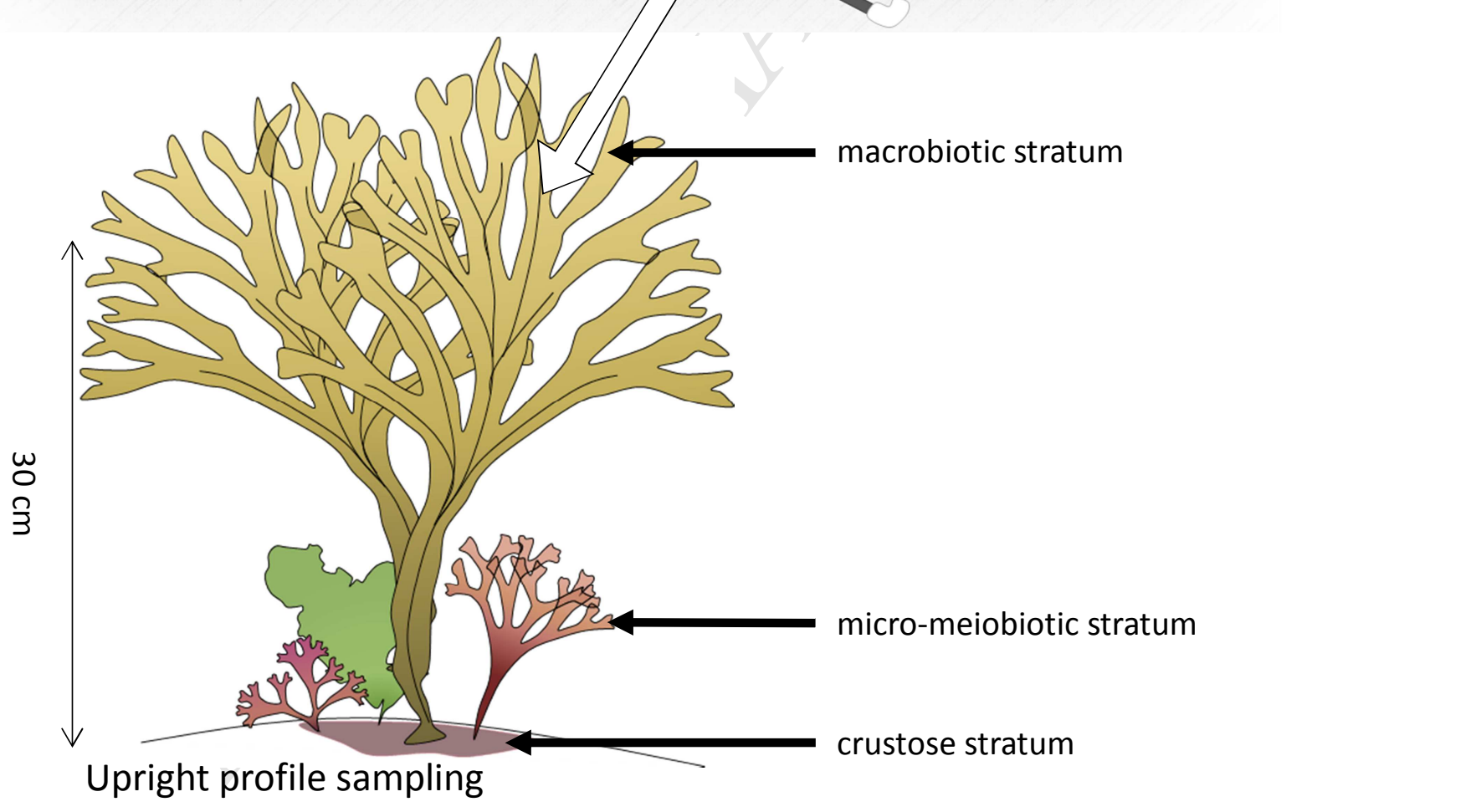

620

621 Figure 2: Description of the two methods of sampling used in the study. Undisturbed

622 sampling takes into account the major groups of macrophytes on the whole structure. upright

623 profilesampling is based on a finer description of the macrophytes species and their canopy

624 and is applied in three quadrats of the structure. 


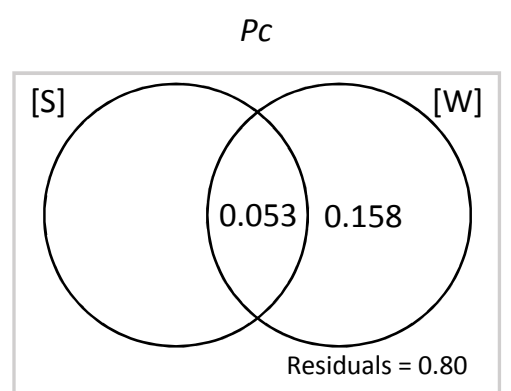

Fser

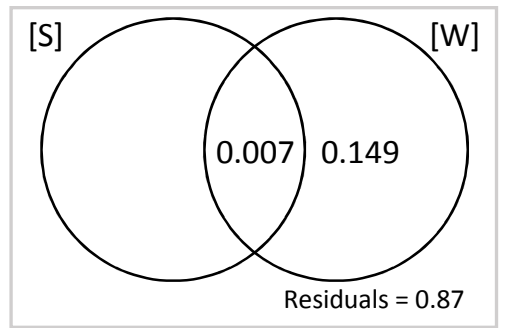

Fspi

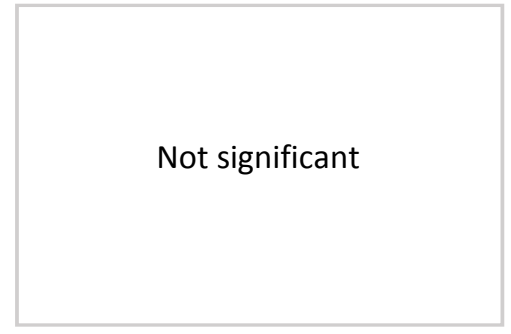

$\mathrm{He}-\mathrm{Bb}$

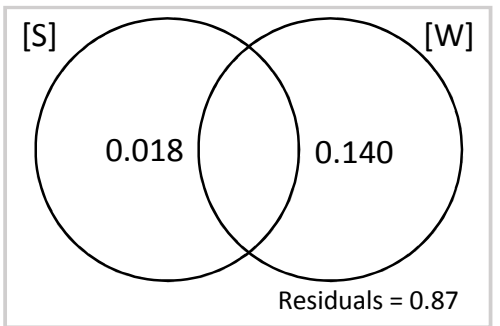

An-Fves

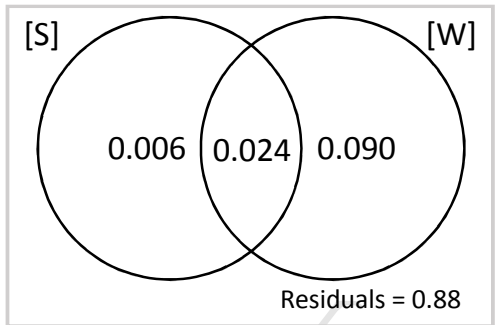

$L d$

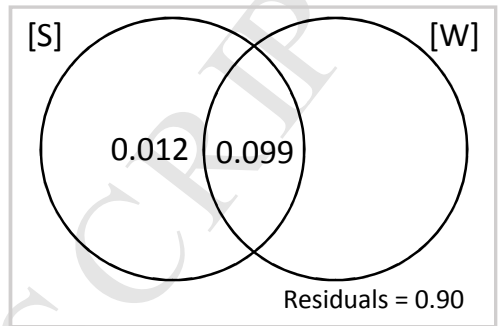

625

626

627

628

629

630

631

632

633

Figure 3: Venn diagrams illustrating the result of variance partitioning for the undisturbed sampling, taking into account the undisturbed sampling data (cover of dominating species of Phaeophyceae, groups of seaweeds), per community with contribution of physical variables. Contribution of each variable is expressed as a fraction of 1 corresponding to a percentage. [S]: site, [W]: wave height. Residuals: unexplained variation. Communities dominated by: Pc = Pelvetia canaliculata, Fspi = Fucus spiralis, An - Fves = Ascophyllum nodosum - Fucus vesiculosus, Fser $=$ Fucus serratus, $\mathrm{He}-\mathrm{Bb}=$ Himanthalia elongata - Bifurcaria bifurcata, $L d=$ Laminaria digitata . 

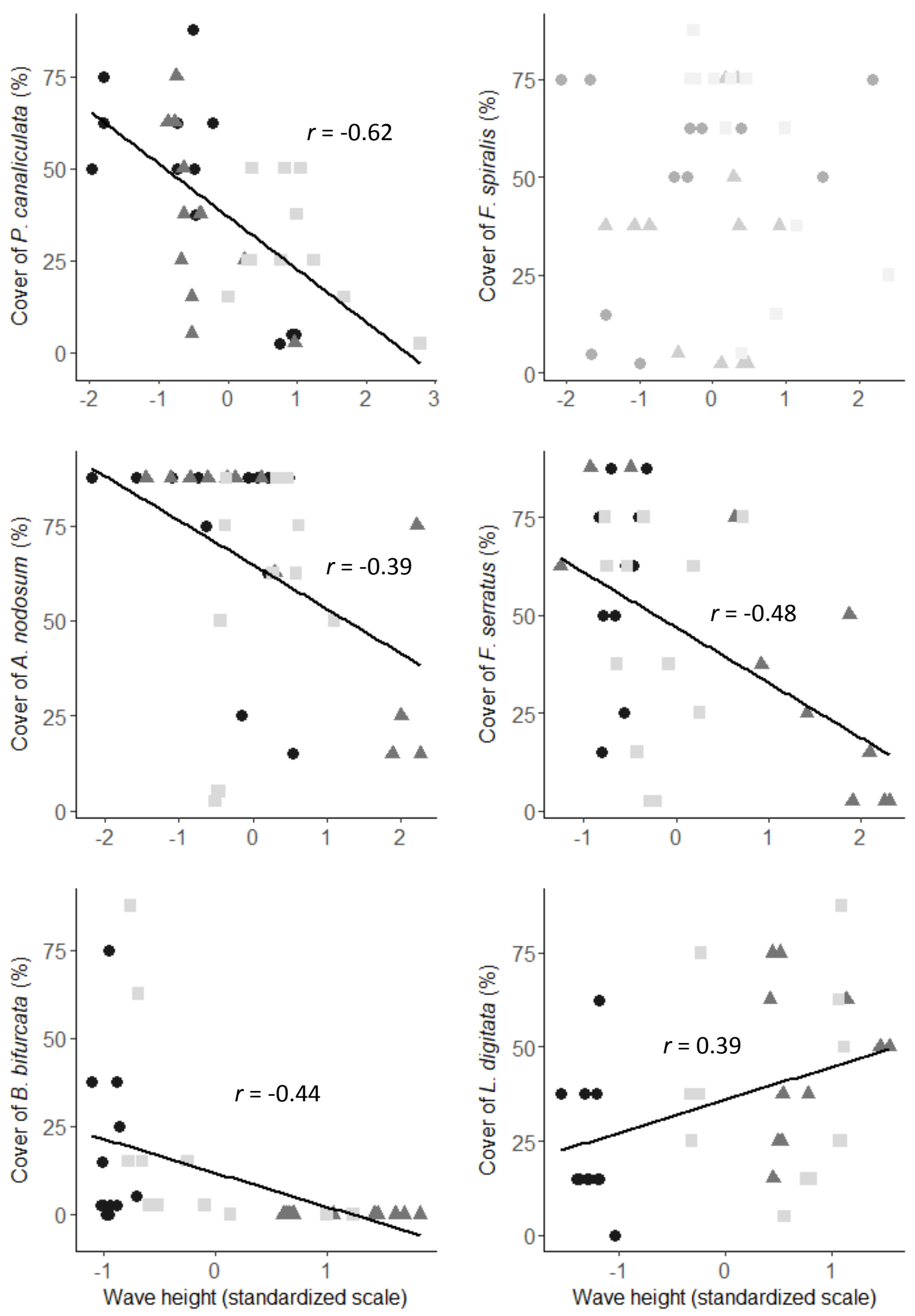

Figure 4: Cover of dominating brown seaweeds in the six studied communities related to normalized wave heights in the case of the undisturbed sampling method. p-value $<0.05$ and $r=$ coefficient of regression. Sites:

Porsal, Segal, $\triangle$ Porspoder 

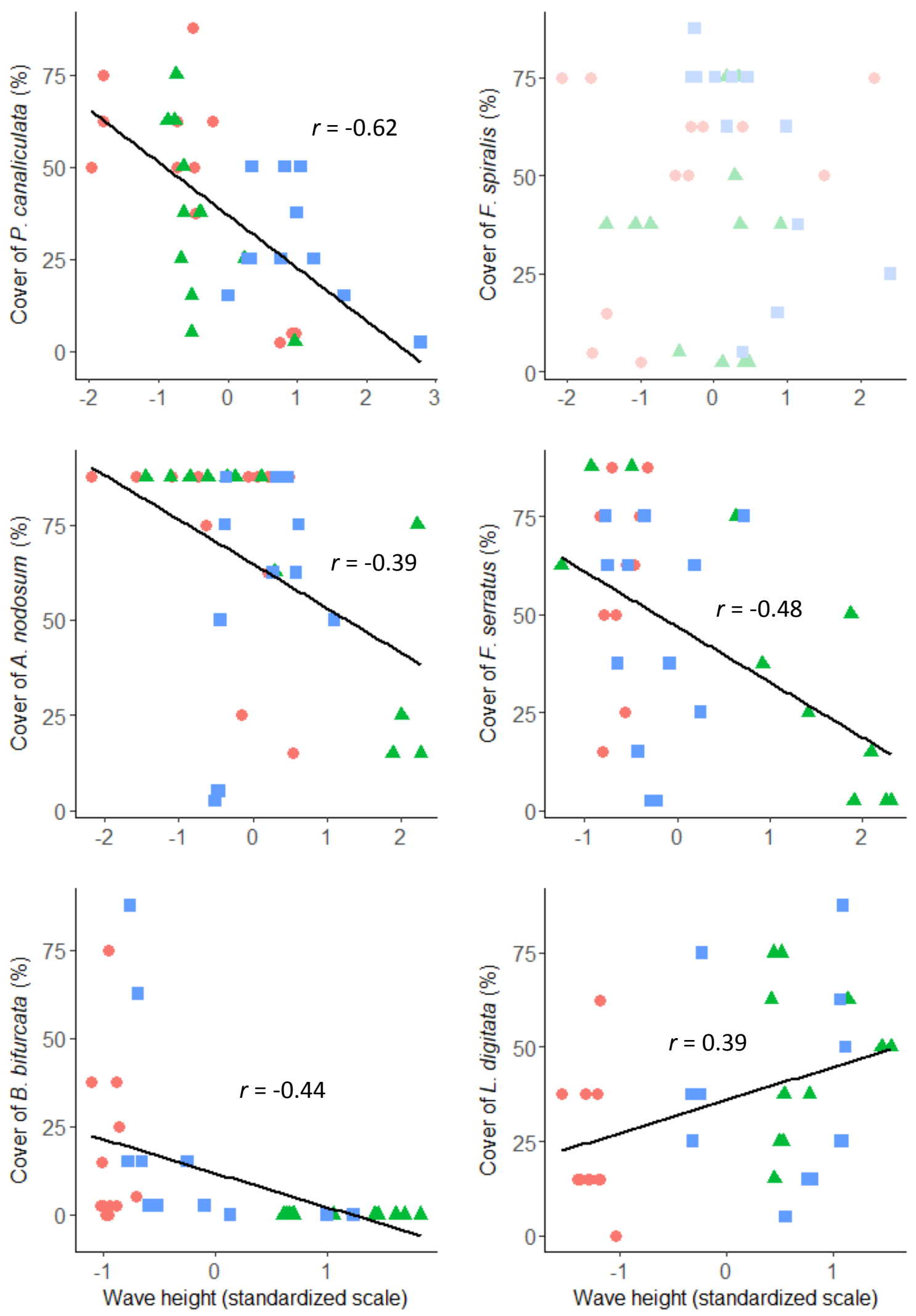

Figure 4: Cover of dominating brown seaweeds in the six studied communities related to 640 normalized wave heights in the case of the undisturbed sampling method. p-value $<0.05$ and $641 r=$ coefficient of regression. Sites: OPorsal, $\quad$ Segal, $\triangle$ Porspoder 


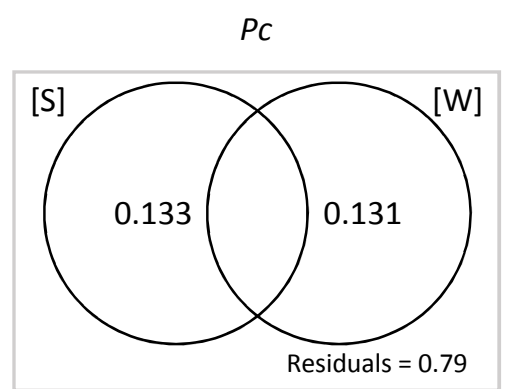

Fser

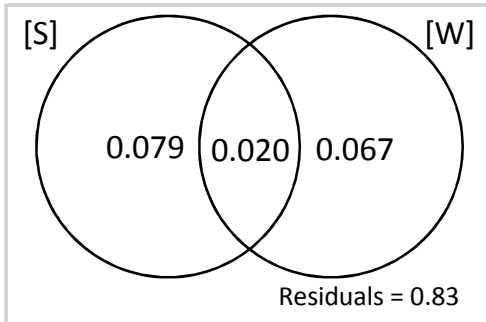

Fspi

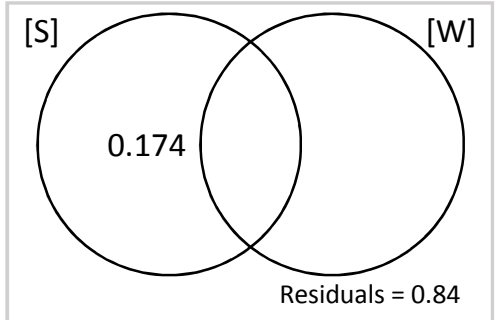

$\mathrm{He}-\mathrm{Bb}$

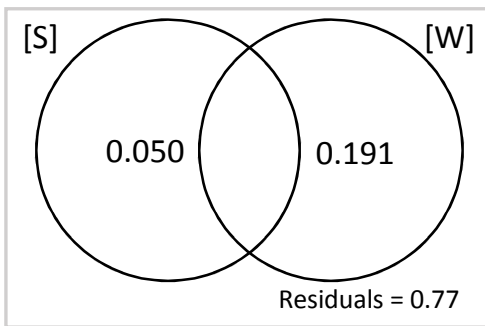

An-Fves

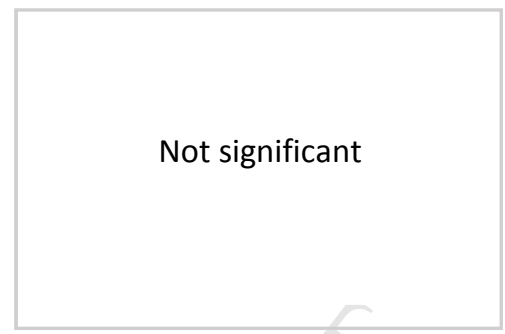

$L d$

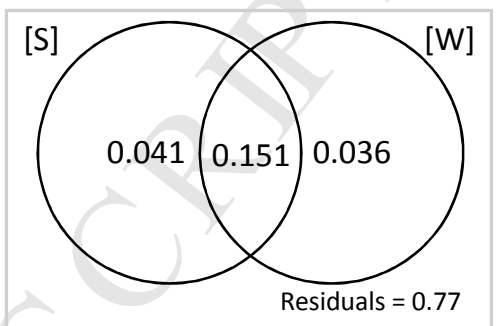

Figure 5: Venn diagrams illustrating the result of variance partitioning for the upright profile

645 sampling, taking into account the cover of every conspicuous seaweed species found in 646 quadrats per community with contribution of physical variables. Contribution of each 647 variable is expressed as a fraction of 1 corresponding to a percentage. [S]: site, [W]: wave 648 height. Residuals: unexplained variation. Communities dominated by: Pc = Pelvetia 649 canaliculata, Fspi $=$ Fucus spiralis, An - Fves = Ascophyllum nodosum - Fucus vesiculosus, 650 Fser $=$ Fucus serratus, He - Bb $=$ Himanthalia elongata - Bifurcaria bifurcata, $L d=$ 651 Laminaria digitata. 

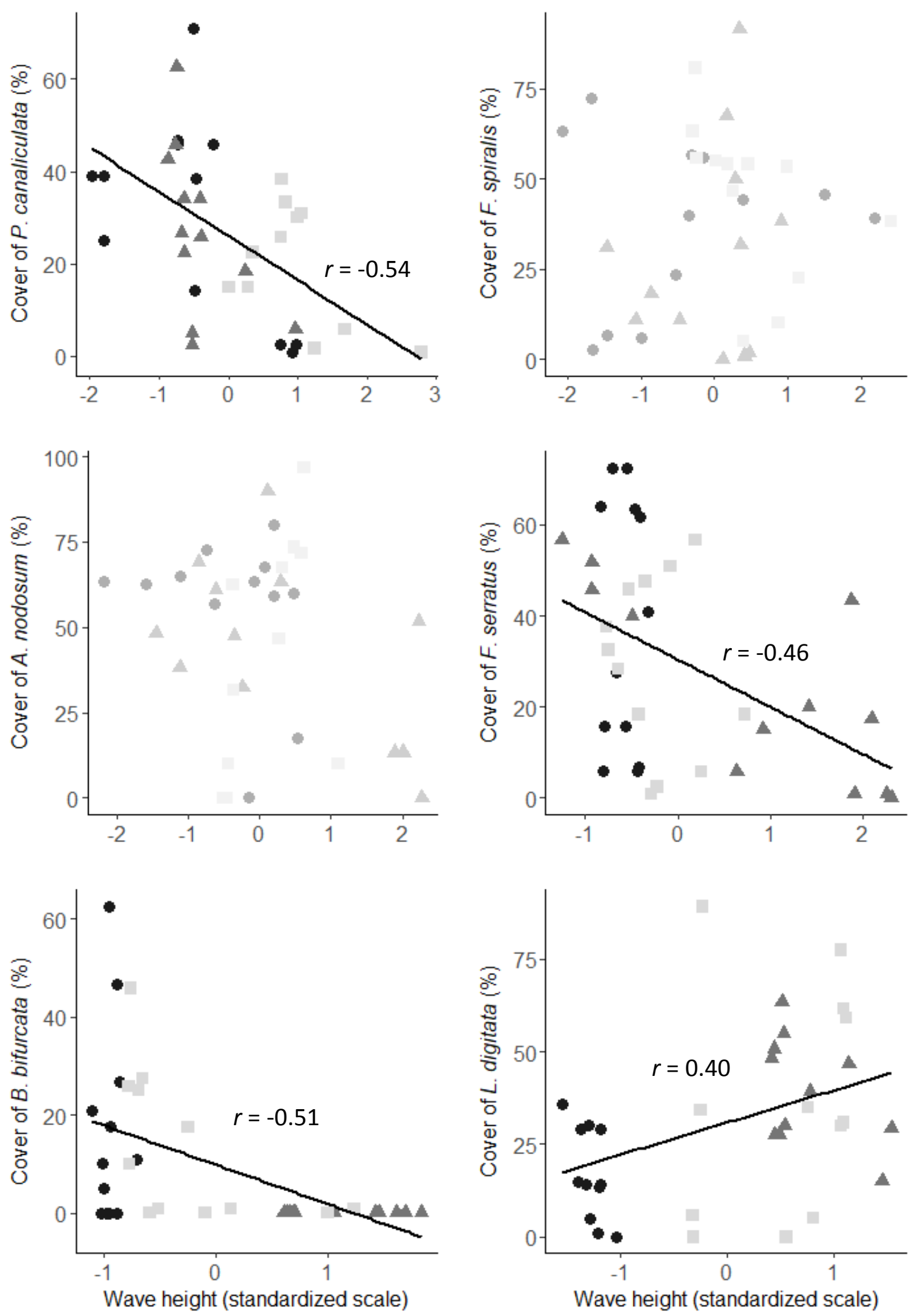

Figure 6: Cover of dominating brown seaweeds in the six communities related to normalized wave heights in the case of the upright profile sampling method. p-value $<0.05$ and $r=$ coefficient of regression. Sites: OPorsal, Segal, $\triangle$ Porspoder 

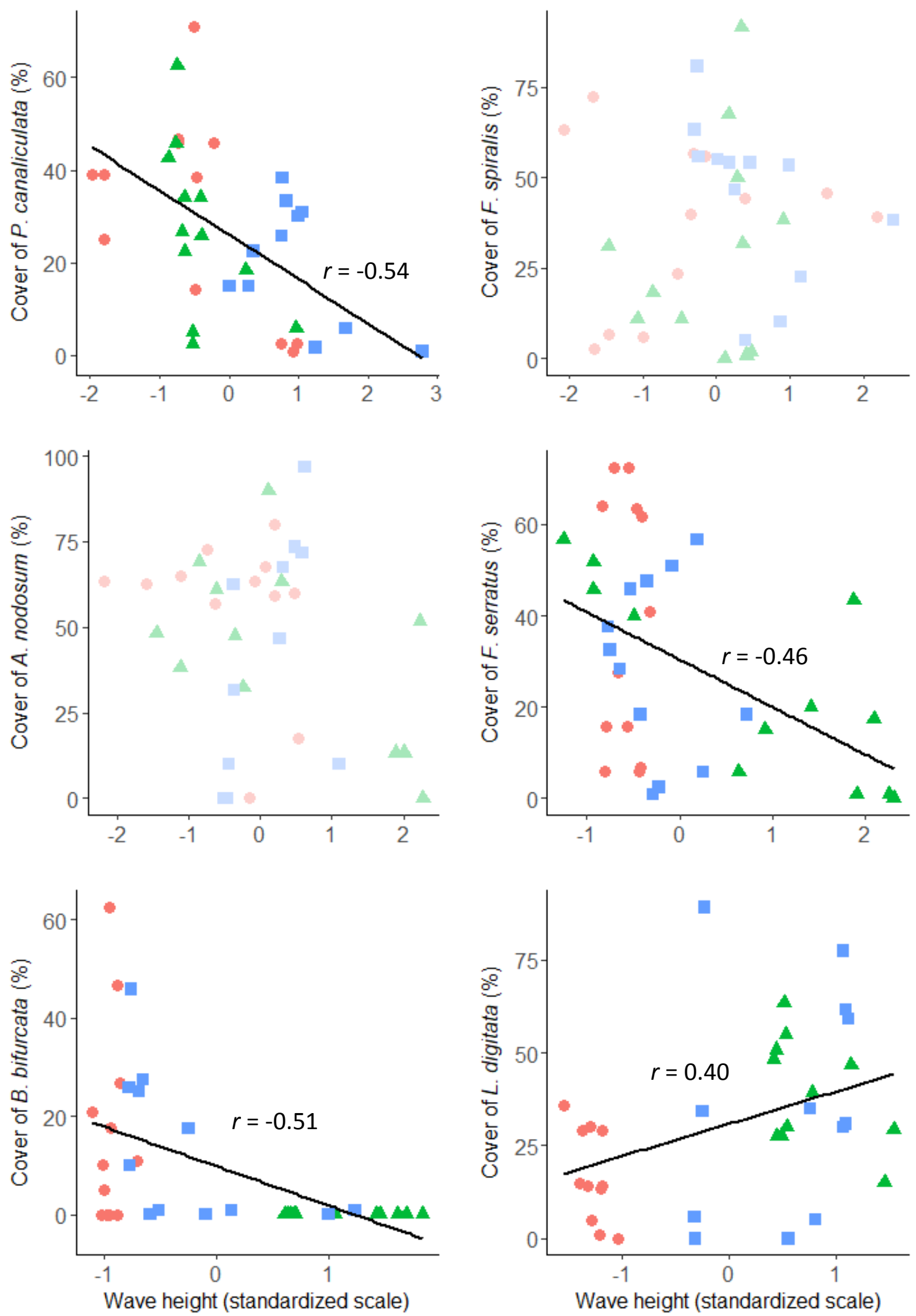

Figure 6: Cover of dominating brown seaweeds in the six communities related to normalized wave heights in the case of the upright profile sampling method. $p$-value $<0.05$ and $r=$ 660 coefficient of regression. Sites: OPorsal, Segal, $\triangle$ Porspoder 
Wave heights have a significant effect on the extent of macroalgal canopies.

Hydrodynamics explains most of intra-community structural variations.

In situ pressure measurements enable small-scale evaluation of wave heights. 